The Open Mechanical Engineering
Bentham OPEN CrossMark
Content list available at: www.benthamopen.com/TOMEJ/
DOI: $10.2174 / 1874155 \mathrm{X} 016100100 \mathrm{D}$

RESEARCH ARTICLE

\title{
Energy Balance Analysis on a Preheating Catalytic Oxidation Device of Coal Mine Ventilation Air Methane
}

\author{
Mao Ming-ming, Liu Yong-qi*, Liu Rui-xiang, Zheng Bin and Meng Jian \\ School of Transportation and Vehicle Engineering, Shandong University of Technology, Zibo 255049, China
}

Received: September 9, 2015

Revised: July 22, 2016

Accepted: July 25, 2016

\begin{abstract}
Energy balance analysis was carried out during the operation process of a preheating catalytic oxidation device of coal mine ventilation air methane. The effects of space velocity, inlet gas temperature and methane volume concentration on each energy balance term were studied. The experimental results show that: the exothermic oxidation power and the surface heat dissipation power loss rise with the increase of methane volume concentration and the oxidation bed inlet temperature, and yet fall when space velocity achieves a high enough value; the exhaust heat power loss is enhanced significantly with the growth of the inlet temperature and space velocity, but the change of methane volume concentration has very little influence on the exhaust heat loss power; the fraction of the exhaust heat loss descends significantly with the increase of methane volume concentration and inlet temperature, and yet rises obviously with the improvement of space velocity. The above results provide a theoretical guidance on the stable selfheating maintenance operation of the preheating catalytic oxidation device.
\end{abstract}

Keyword: Catalytic oxidation, Energy balance, Parametric study, Ventilation air methane.

\section{INTRODUCTION}

In order to improve the safety of coal mine production, the Ventilation Air Methane (VAM) is usually exhausted by a great deal of ventilation. Methane, the main component of VAM, is the second largest greenhouse gas after carbon dioxide. However, it is also a kind of clean gas energy. China is one of the largest coal producers and the annual emission of pure methane through VAM exceeds 150 billion cubic meters. It causes not only huge waste of the renewable energy resource but also serious pollution of the atmospheric environment [1 - 5].

It is difficult to burn the VAM directly by the traditional burner for its low concentration (generally $0.1 \% \sim 0.75 \%$ ) and large fluctuation of volume concentration and flow rate [6 - 10]. According to the character of the VAM, Shandong University of Technology of China proposed a preheating catalytic oxidation technology, which could effectively oxidize the VAM by a honeycomb ceramic oxidation bed loaded by the noble metal Pd catalyst [11 - 15]. In addition, the heat of the exhaust can be recycled by a recuperative heat exchanger to achieve the thermal equilibrium state to maintain the self-heating maintenance operation. This technology brings a stable and reliable temperature field and high heat recovery efficiency with compact structure and small flow resistance, so it is very economical and feasible.

Because the methane content of the inlet stream is very low, the key to the successful operation of preheating catalytic oxidation device is whether a thermal equilibrium state during the catalytic oxidation reaction can be reached. The thermal equilibrium is a balance between the released heat by the catalytic oxidation reaction and the heat taken away by the exhaust and dissipated on the device surface.

In the operation of the device, the operating parameters have a great influence on the catalytic oxidation heat release, the exhaust heat loss and the surface heat dissipation loss. The influence plays an important role for the design

\footnotetext{
* Address correspondence to this author at the School of Transportation and Vehicle Engineering, Shandong University of Technology, Zibo 255049, China; Tel/Fax: +86 533 2782616; E-mail: liuyongqi65@163.com, shandongmao@163.com
} 
guidance of the heat exchanger and the insulation layer. Previous studies about the VAM catalytic oxidation focused on methane conversion rate, stability of temperature field and heat extraction performance [16 - 20], while the analysis on the device overall thermal equilibrium and the research of the effects of the operating parameters on the heat loss are very lacking. Thereby the thermal equilibrium is analyzed in the running process of a coal mine VAM preheating catalytic oxidation device, and the influence of several important operating parameters, including inlet stream methane volume concentration, space velocity and oxidation bed inlet temperature on the energy balance terms to maintain the thermal equilibrium is investigated. The above research can provide an important theoretical guidance for the optimal design and the stable self-heating maintenance operation of the oxidation device.

\section{EXPERIMENTAL METHOD}

The coal mine VAM preheating catalytic oxidation device is shown in Fig. (1). The whole system mainly includes a reaction chamber, the gas supply system, the preheating system, the startup/auxiliary heating system, and the measurement and control system. The catalytic oxidation bed in the reaction chamber is the core part of the device, which is packed by the cordierite honeycomb ceramic blocks. The catalytic oxidation bed has a length of $1050 \mathrm{~mm}$ and the cross section is $600 \mathrm{~mm} \times 600 \mathrm{~mm}$ square. The honeycomb ceramic blocks have a large number of square channels with hole density of 17.3 PPI. The block size is $150 \mathrm{~mm} \times 150 \mathrm{~mm} \times 150 \mathrm{~mm}$ and the honeycomb porosity is about $60 \%$. The inner wall of the honeycomb ceramic hole is coated by the catalyst with the active ingredient of noble metal palladium. The air supply system, mainly including a fan, a fan inverter, a compressed natural gas cylinder and a pressure regulating box, can supply the methane-air mixture with a volume concentration of less than $1 \%$. The preheating system uses a recuperative heat exchanger to recycle the exhaust gas to heat the inlet stream. There is a twoway corrugated plate for heat transfer enhancement inside of the recuperative heat exchanger. The startup/auxiliary heating system is composed by an electric heater and a control cabinet, which can heat the oxidation bed to the oxidation temperature of methane in the initial operation of the device. The measurement and control system mainly conducts the oxidation bed temperature measurement, the gas flow rate measurement, the pressure difference measurement and the gas composition analysis, and adjust the inlet flow rate and volume concentration.

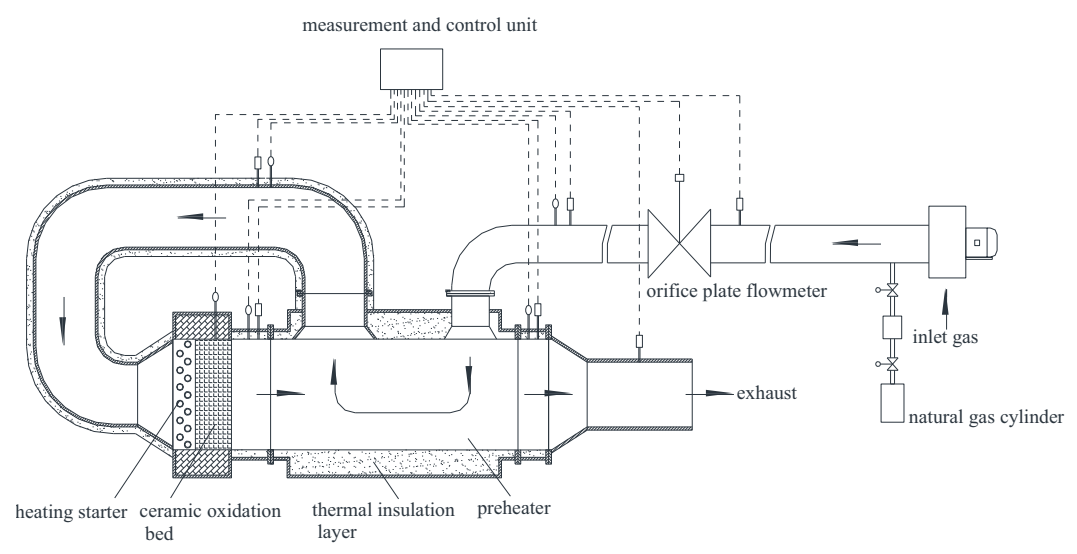

Fig. (1). Diagram of preheating catalytic oxidation reactor.

The total flow rate of the gas is measured by the orifice plate flow meter, whose measuring range is $0 \sim 1500 \mathrm{Nm}^{3} / \mathrm{h}$, and the measurement accuracy is $1 \%$. The temperature and pressure difference of the cold side and the hot side of the preheater are both measured by the KIMO TPS-08-500-T type pitot tube and the CP200 type micro differential pressure transmitter, and the measurement accuracy is $4 \%$. Methane volume concentration at the inlet and outlet of the device is real-time monitored by the $\mathrm{GJG} 10 \mathrm{H}(\mathrm{C})$ type pipeline infrared methane concentration sensor manufactured by Chongqing branch of China Coal Research Institute, with the measurement range 0 to $1 \%$, error within $\pm 0.07 \%$, and response time 20s. To acquire more accurate experimental data when the energy balance state is achieved, the methane volume concentration in the inlet and outlet of the device is measured by the J2KN type flue gas analyzer of German RBR company, and the accuracy is $1 \mathrm{ppm}$.

The oxidation bed structure is shown in Fig. (2a), which is composed of the first layer of the ceramic without catalyst and the back seven layers of the catalyst supported ceramic. The thickness of each layer is $150 \mathrm{~mm}$. The first ceramic layer has a $\mathrm{K}$ type thermocouple in the center to measure the inlet temperature of the oxidation bed and evens 
the inlet flow and temperature. In the catalytic oxidation bed, four temperature measurement cross sections are arranged, with five $\mathrm{K}$ type thermocouples at each section for temperature measurement. The arrangement of measuring points is shown in Fig. (2b). The temperature measuring point is assigned respectively in the cold and hot side of the heat exchanger to obtain the inlet stream temperature and the exhaust temperature, which is shown in Fig. (2c).

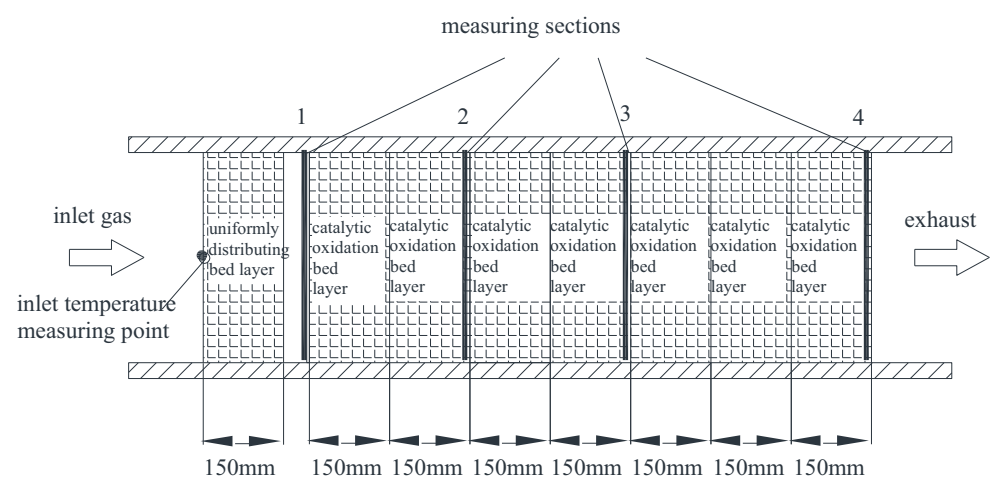

(a) Temperature measurement section arrangement of oxidation bed

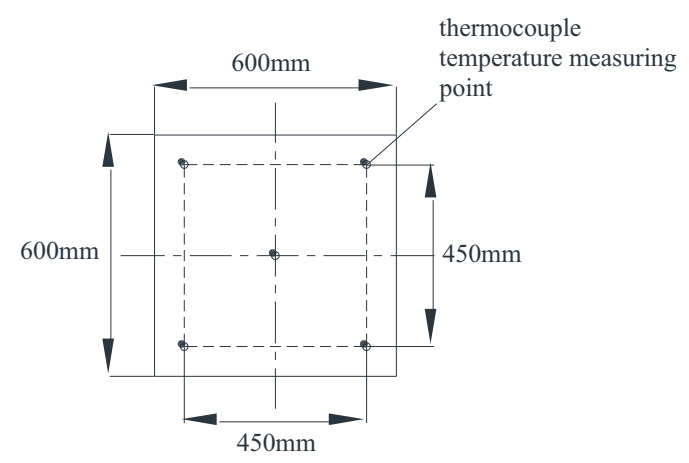

(b) Sectional temperature measurement points arrangement

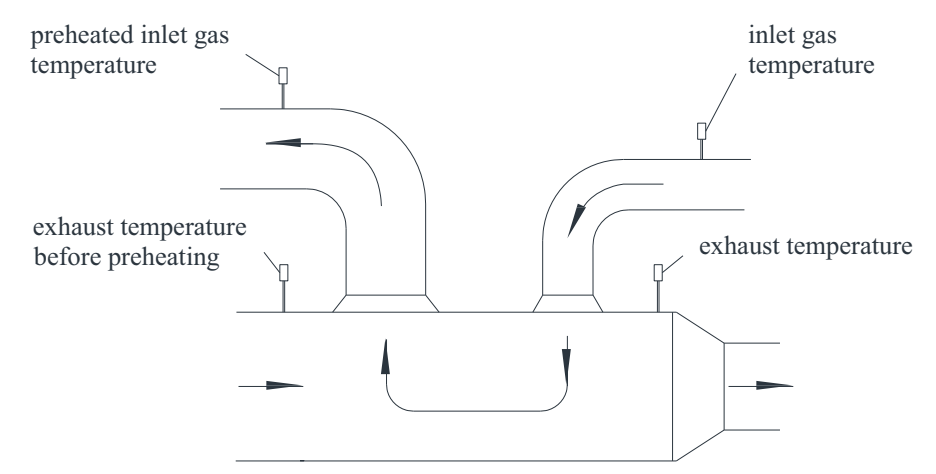

(c) Heat exchanger temperature measurement points arrangement

Fig. (2). Temperature measurement points arrangement of the reactor.

The operation principle of the preheating catalytic oxidation device is shown in Fig. (1). Firstly, the electric heater turns on under a small flow rate to heat the oxidation bed rapidly until the fresh VAM oxidation temperature is achieved. Then the methane gas is mixed into the inlet stream. The methane-air mixture is catalytically oxidized in the oxidation bed and the oxidation heat is released and divided into two parts. One part is absorbed by the oxidation bed and the other part preheats the unreacted inlet stream through the heat exchanger. The cooled exhaust is finally discharged into the atmosphere. When the preheated inlet stream temperature rises high enough for the methane-air 
mixture catalytic oxidation in the oxidation bed, the electric heater is turned off and the device achieves self-heating maintenance operation relying on the exothermic oxidation heat and the heat feedback of the heat exchanger.

\section{ENERGY BALANCE ANALYSIS METHOD}

Because of the limited performance of the thermal insulation layer, the device has surface heat dissipation loss. In addition, the exhaust gas takes away a part of the methane exothermic oxidation heat which could not be recovered and the exhaust heat loss is produced. During the experimental process, in order to adjust the operation parameters conveniently, such as space velocity, inlet concentration and inlet temperature, and study the influence of each parameter on the heat loss, the electric heater stays turned on all the time. The condition for the preheating catalytic oxidation device to reach the thermal equilibrium state is that the sum of the heating power of the methane exothermic oxidation heat and the electric heater equals the sum of the surface heat dissipation loss power and the exhaust heat loss power. When the inlet stream parameter is changed, the temperature field of the oxidation bed varies subsequently and will achieve a new energy equilibrium state after a period of time. This is a slow process for the large thermal inertia of the oxidation bed. If the temperature field keeps essentially the same for at least twenty minutes, the energy equilibrium state is achieved and the measuring data will be collected.

\subsection{Calculation of the Methane Exothermic Oxidation Power}

For the calculation of the methane exothermic oxidation power, the complete oxidation reaction equation of methane is $\mathrm{CH}_{4}+2 \mathrm{O}_{2}=\mathrm{CO}_{2}+2 \mathrm{H}_{2} \mathrm{O}+L H V$, and the complete exothermic oxidation heat $L H V$ is $802.7 \mathrm{~kJ} . \mathrm{mol}^{-1}$, so the formula of methane exothermic oxidation power is as follows:

$$
\Phi_{1}=q_{v} \eta x_{\mathrm{CH}_{4}, \text { in }} L H V / V_{m o l}
$$

Where, $\Phi_{l}$ is the methane exothermic oxidation power in $\mathrm{kW}, q_{v}$ is the volume flow rate of methane-air mixture into the device per unit time in the standard condition in $\mathrm{L} \cdot \mathrm{s}^{-1}, \eta$ is the methane conversion rate, $x_{C H 4, \text { in }}$ is the methane volume concentration, and $V_{m o l}$ is the gas molar volume in the standard condition with the value of $22.4 \mathrm{~L} \cdot \mathrm{mol}^{-1}$.

\subsection{Calculation of the Exhaust Heat Loss Power}

The high-temperature exhaust gas generated after the methane oxidation reaction preheats the fresh inlet stream through the heat exchanger. Due to the limited heat transfer capability, the temperature of the exhaust gas is still high which leads to the exhaust heat loss. The formula for the calculation of the exhaust heat loss power is as follows:

$$
\Phi_{2}=q_{v} \alpha\left(c_{\text {pout }} T_{\text {out }}-c_{\text {pin }} T_{\text {in }}\right)
$$

Where, $\Phi_{2}$ is the exhaust heat loss power in $\mathrm{kW}, \rho$ is the inlet stream density in the standard condition in $\mathrm{kg} \cdot \mathrm{L}^{-1}, c_{\text {pout }}$ is the specific heat at constant pressure of the exhaust gas, $c_{\text {pin }}$ is the specific heat at constant pressure of the inlet stream gas, both in $\mathrm{J} \cdot \mathrm{kg}^{-1} \cdot \mathrm{K}^{-1}$, and $T_{\text {in }}$ is the inlet stream temperature in $\mathrm{K}$. Because the methane concentration of the inlet stream is very low (less than $1 \%$ ), the specific heat capacity of the inlet stream and exhaust is calculated according to the air.

\subsection{Calculation of the Surface Heat Dissipation Power}

Under the condition that the preheating catalytic oxidation device achieves the thermal equilibrium state, the surface heat dissipation power can be calculated by the following formula:

$$
\Phi_{3}=\Phi_{1}-\Phi_{2}+\Phi_{4}
$$

Where, $\Phi_{3}$ is the surface heat dissipation power, and $\Phi_{4}$ is the heating power of the starter, both in $\mathrm{kW}$.

\section{THE EFFECTS OF THE OPERATING PARAMETERS}

\subsection{The Transient Variation of the Performance Parameters During Operation}

After the startup of the preheating catalytic oxidation device is completed, in order to study the effects of the operating parameters on the heat loss, firstly the space velocity is set as a fixed value through the frequency conversion fan, then the inlet gas temperature of the oxidation bed is determined by the heating power of the electric heater, finally 
the inlet gas concentration is adjusted by the ratio of the methane through the gas supply system, so the performance can be obtained under different operating parameters. Fig. (3) shows the transient variation of the average temperature of the oxidation bed under the space velocity of $6400 \mathrm{~h}^{-1}$. From Fig. (3) it can be seen that the average temperature of the oxidation bed rises rapidly in the startup stage, and the methane is incorporated into the inlet gas after the methane catalytic oxidation temperature (about $420^{\circ} \mathrm{C}$ ) is reached. In the catalytic oxidation stage, the inlet temperature is increased gradually from $450^{\circ} \mathrm{C}$ to $550^{\circ} \mathrm{C}$, and the average temperature of the oxidation bed also rises and keeps very close to it. When the methane volume concentration is improved from $0.6 \%$ to $1.0 \%$, the average temperature of the oxidation bed is almost unchanged. This is because the concentration of the inlet stream is very low, and the change of the oxidation heat release has no obvious effect on the average temperature of the oxidation bed.

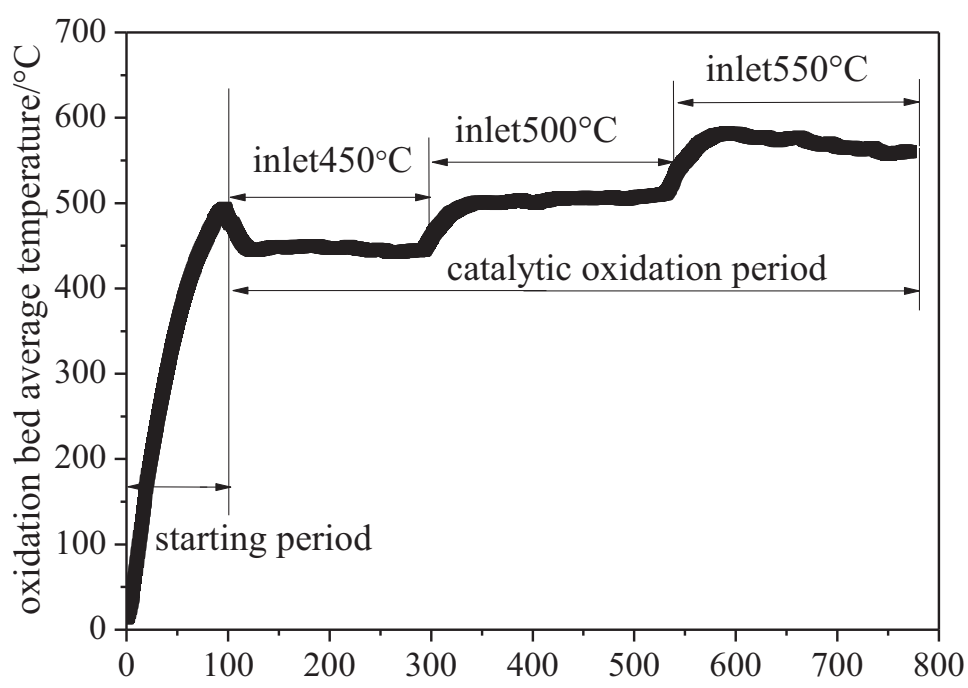

Fig. (3). Change of oxidation bed average temperature with time with space velocity of $6400 \mathrm{~h}^{-1}$.

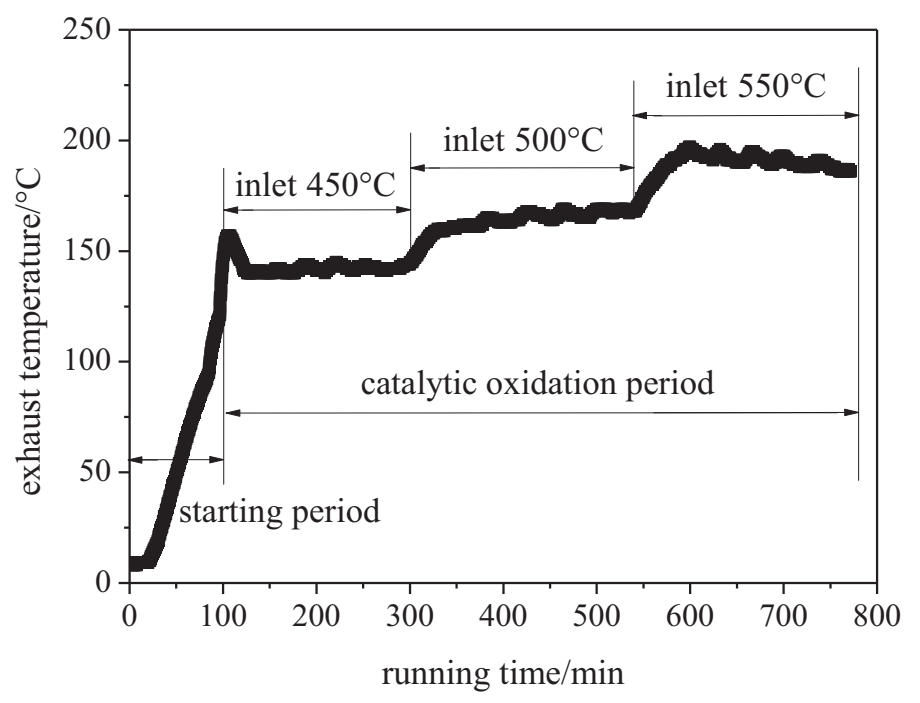

Fig. (4). Change of exhaust temperature with time with space velocity of $6400 \mathrm{~h}^{-1}$.

Figs. (4 and 5) are respectively the variation of the exhaust and preheated inlet gas temperature with time under the space velocity of $6400 \mathrm{~h}^{-1}$. The temperature of the exhaust and the preheated inlet stream both have obvious delay compared with the average temperature of the oxidation bed, because the released oxidation heat is absorbed and stored 
firstly by the oxidation bed, and then the excessive heat is discharged with the exhaust gas and preheat the inlet stream through the recuperative exchanger. Fig. (4) shows that the exhaust maintains a high level temperature (about $130^{\circ} \mathrm{C}$ $\sim 170^{\circ} \mathrm{C}$ ) and increases significantly with the rise of the average temperature of the oxidation bed, so a great exhaust heat loss is generated due to the uncycled heat. Fig. (5) shows that although the preheated inlet stream temperature improves obviously with the inlet temperature of the oxidation bed, it still never reaches the ignition temperature (about $420^{\circ} \mathrm{C}$ ) for the methane-air mixture catalytic oxidation in the oxidation bed. In addition, the temperature of the preheated inlet stream falls further due to the heat loss before the arrival at the entrance of the oxidation bed, so a secondary heating is necessary besides the preheating. With the increase of the inlet temperature of the oxidation bed, the preheated inlet stream temperature is obviously improved, which indicates that more exhaust heat is recycled, and it is beneficial for the device to achieve the self-heating maintenance state.

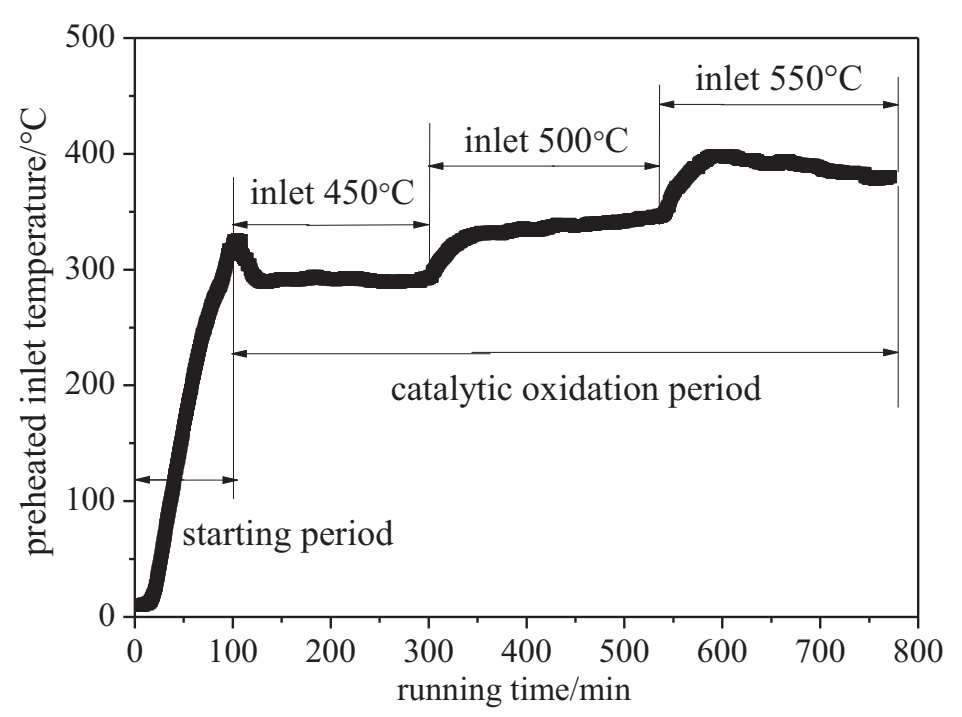

Fig. (5). Change of preheated inlet gas temperature with time with space velocity of $6400 \mathrm{~h}^{-1}$.

\subsection{The Effects of the Methane Volume Concentration Under Different Space Velocities}

The inlet stream methane concentration, space velocity and the inlet temperature of the oxidation bed are all important parameters during the running of the preheating catalytic oxidation device, and have significant influence on the heat loss in the process of the methane catalytic oxidation. In the study of the influence of the methane volume concentration, the inlet temperature of the oxidation bed is fixed to $600^{\circ} \mathrm{C}$, the methane volume concentration ranges $0.6 \% \sim 1.0 \%$, and the inlet stream space velocity ranges $4000 \mathrm{~h}^{-1} \sim 7200 \mathrm{~h}^{-1}$. Fig. (6a-c) show the influence of the methane volume concentration on the methane exothermic oxidation power, the exhaust heat loss power and the surface heat dissipation power, respectively. It can be seen from Fig. (6a), the exothermic oxidation power all increases rapidly under three space velocities when the methane volume concentration is improved from $0.6 \%$ to $1.0 \%$. The methane exothermic oxidation power gets a big jump when the space velocity grows from $4000 \mathrm{~h}^{-1}$ to $6400 \mathrm{~h}^{-1}$, and however has a slight drop when the space velocity grows from $6400 \mathrm{~h}^{-1}$ to $7200 \mathrm{~h}^{-1}$. This is due to the decreased methane conversion rate under the excessive space velocity. Fig. (6b) shows that the methane volume concentration has small influence on the exhaust heat loss power because the inlet stream concentration is quite low and has little effect on the exhaust temperature. Fig. (6c) shows that the surface heat dissipation power increases significantly with the rise of the concentration especially under higher space velocity because the methane oxidation releases more heat absorbed by the oxidation bed under higher methane volume concentration which enhances the heat exchange between the reaction chamber and the environment. When the space velocity is increased to $7200 \mathrm{~h}^{-1}$, the surface heat dissipation power begins to decline. This is because the methane conversion rate decreases under the high inlet space velocity for short residence time. Then the average temperature of the oxidation bed drops and the heat exchange between the oxidation bed and the environment weakens. 
Fig. (7) shows the variation of the fraction of the total heat loss accounted by the exhaust heat loss with the methane volume concentration. This fraction obviously decreases with the increase of the methane volume concentration, which indicates that the heat exchange between the reaction chamber and the environment gets stronger and more heat is dissipated through the device surface when the catalytic oxidation becomes more intense. While the exhaust heat loss still accounts for far more than $50 \%$ of the total heat loss under each methane volume concentration, so it always occupies the dominant. With the rise of the space velocity, the fraction of the exhaust heat loss increases significantly, because the shorter residence time isn't enough for the heat exchange between the exhaust and the oxidation bed and thus much heat is taken away by the exhaust.

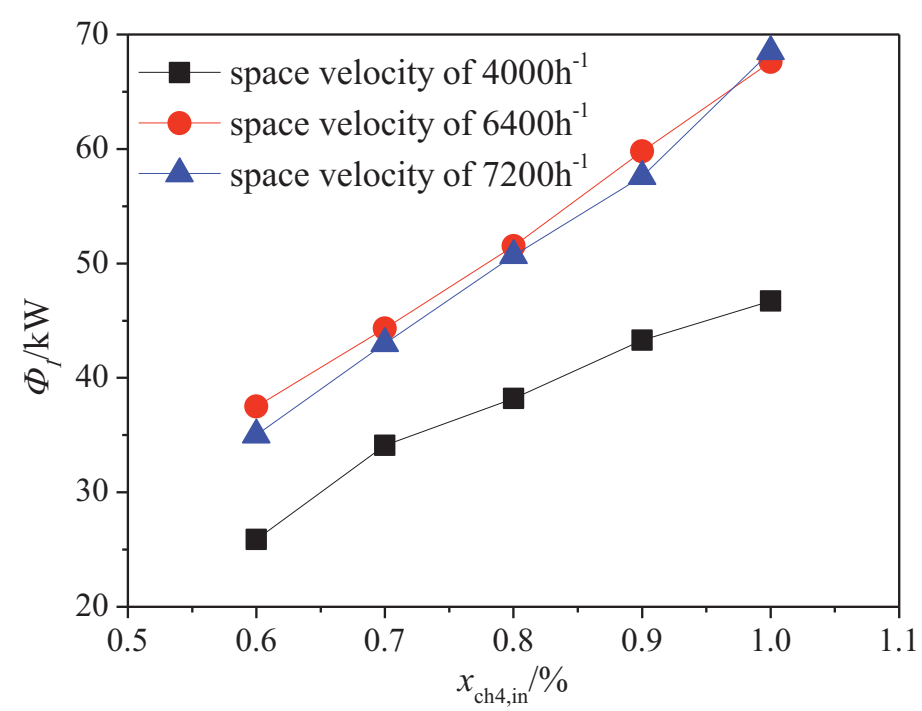

(a) Exothermic oxidation power

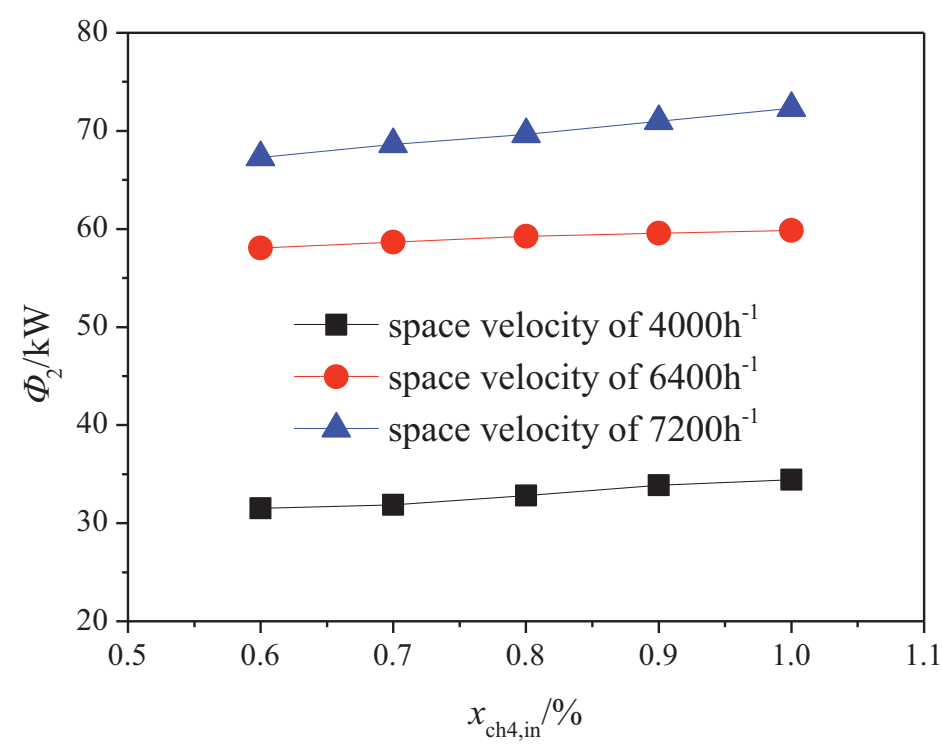

(b) Exhaust heat loss power 


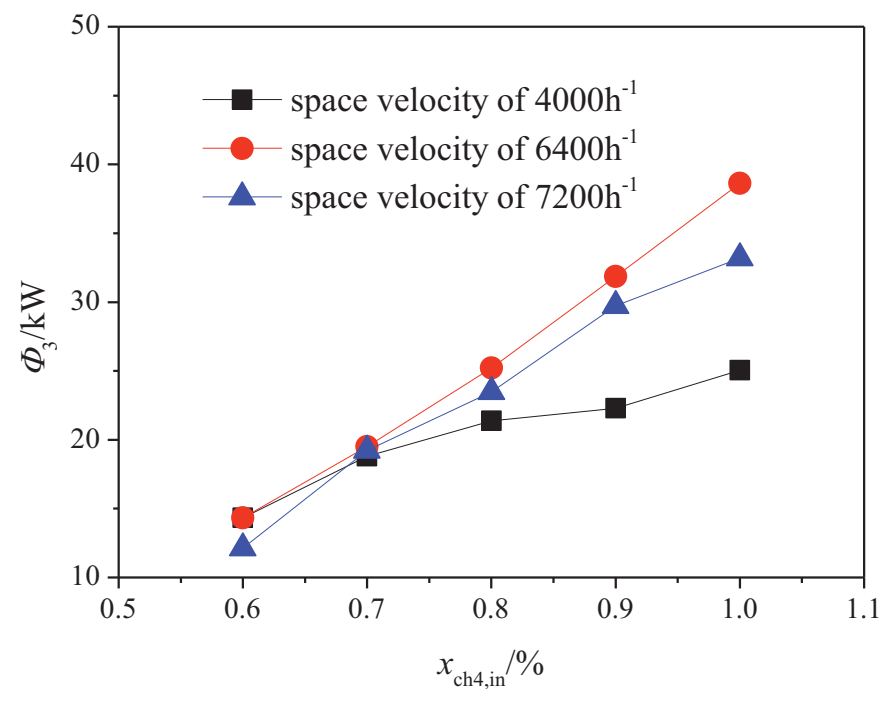

(c) Surface heat dissipation power

Fig. (6). Effects of methane volume concentration on the energy balance terms under different space velocities.

The main method for the reduction of the exhaust heat loss is to increase the heat exchange area of the exchanger to improve the heat recovery efficiency and for the reduction of the surface heat dissipation loss is to increase the insulation layer thickness or replace it for other insulation materials with lower thermal conductivity. According to the character of the heat loss under various operating conditions, the exhaust heat loss should be controlled emphatically under condition with low inlet stream methane volume concentration and high space velocity, while the surface heat dissipation loss should be controlled emphatically under condition with high inlet stream methane volume concentration and low space velocity. In the whole range of the operating parameters of the preheating catalytic oxidation device, the heat exchanger and the insulation layer should be optimized according to the operating condition with high inlet space velocity and high inlet concentration.

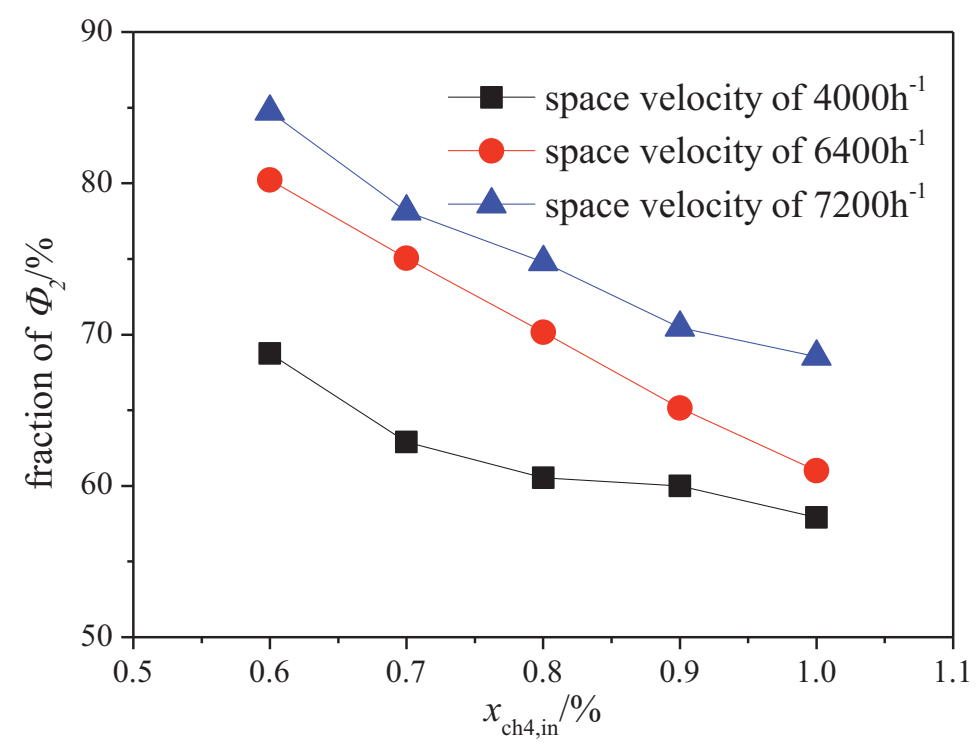

Fig. (7). Change of fraction of the exhaust heat loss with concentration under different space velocities. 


\subsection{The Effects of the Inlet Temperature of the Oxidation Bed Under Different Space Velocities}

During the study of the inlet temperature of the oxidation bed under different space velocities, the inlet stream methane volume concentration is fixed to $1 \%$, the inlet temperature of the oxidation bed ranges $450^{\circ} \mathrm{C} \sim 600^{\circ} \mathrm{C}$ and the inlet stream space velocity ranges $4000 \mathrm{~h}^{-1} \sim 7200 \mathrm{~h}^{-1}$ Fig. ( $\left.\mathbf{8 a}-\mathbf{c}\right)$ show the effect of the inlet temperature of the oxidation bed on the methane exothermic oxidation power, the exhaust heat loss power and the surface heat dissipation power respectively, for different space velocities. Fig. (8a) shows with the increase of the inlet temperature, the methane exothermic oxidation power evidently increases especially under high inlet stream space velocity, because the methane conversion rate is improved by the high inlet temperature particularly under high inlet stream space velocity. So the methane exothermic oxidation power under the space velocity of $6400 \mathrm{~h}^{-1}$ and $7200 \mathrm{~h}^{-1}$ is much higher than that under the space velocity of $4000 \mathrm{~h}^{-1}$ when the inlet temperature is increased above $500^{\circ} \mathrm{C}$. Thus as long as the inlet temperature of the oxidation bed exceeds $500^{\circ} \mathrm{C}$, the methane mixture can be fully oxidized under the space velocity of $4000 \mathrm{~h}^{-1}$. Fig. (8b) shows the exhaust heat loss power increases with the increase of the inlet temperature. The reason is that the higher inlet temperature leads to the higher exhaust gas temperature. For the high inlet space velocity, the methane conversion rate increases with higher inlet temperature, so the exhaust gas temperature rises rapidly. Fig. (8c) shows that the surface heat dissipation power grows obviously with the increase of the inlet temperature for the two higher space velocities, while for the lower space velocity no striking changes are observed above $500{ }^{\circ} \mathrm{C}$. This is because the methane has been essentially oxidized and the oxidation heat has been fully released under the lower space velocity, however the methane conversion rate is still rising with the increased inlet temperature under the higher space velocity, so the further released heat enhances the heat exchange between the reaction chamber and the environment.

Fig. (9) shows the variation of the exhaust heat loss fraction of the total heat loss with the inlet temperature of the oxidation bed. It's clear that the fraction of the exhaust heat loss presents a general decreasing trend with the increase of the oxidation bed inlet temperature under the two higher space velocities, while much less affected under the low space velocity. This is owing to that the methane conversion rate is more easily affected by the inlet temperature under the higher space velocity, so the oxidation heat release obviously increases and the surface heat dissipation is strengthened, and thus the fraction of the surface heat dissipation rises. It's evident that the exhaust heat loss accounts for well over $50 \%$ of the total heat loss and occupies absolute dominance under the two higher space velocities, yet the fraction of the exhaust heat loss and surface heat dissipation are very close under the low space velocity. Thus the heat loss control should focus on the control of the exhaust heat loss under the condition with high space velocity and low inlet temperature and attaches equal importance to both heat losses under the condition with low space velocity. In the whole operating conditions the heat exchanger and insulation layer should be reasonably designed aiming at the condition with high space velocity and high inlet temperature of the oxidation bed.

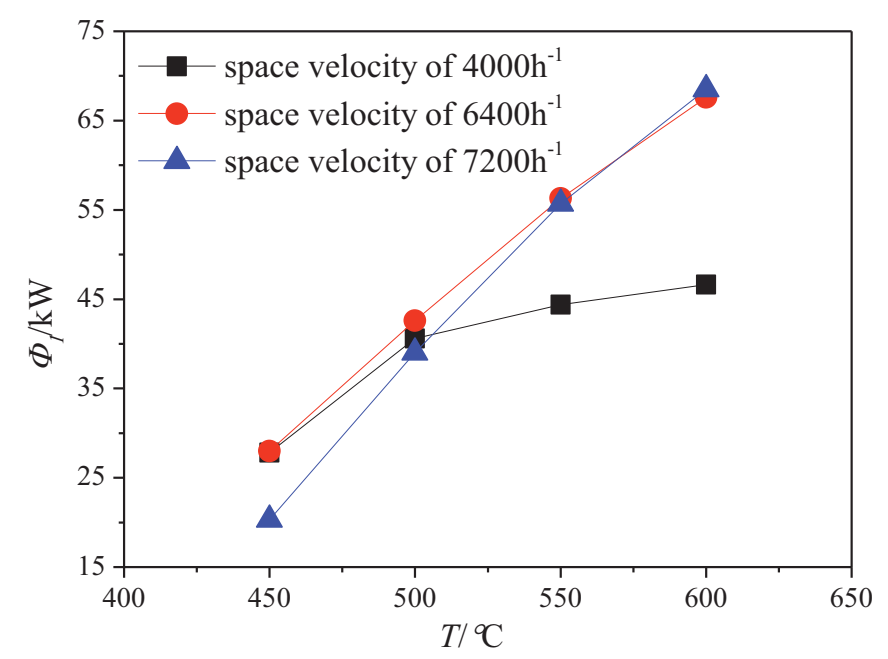

(a) Exothermic oxidation power 


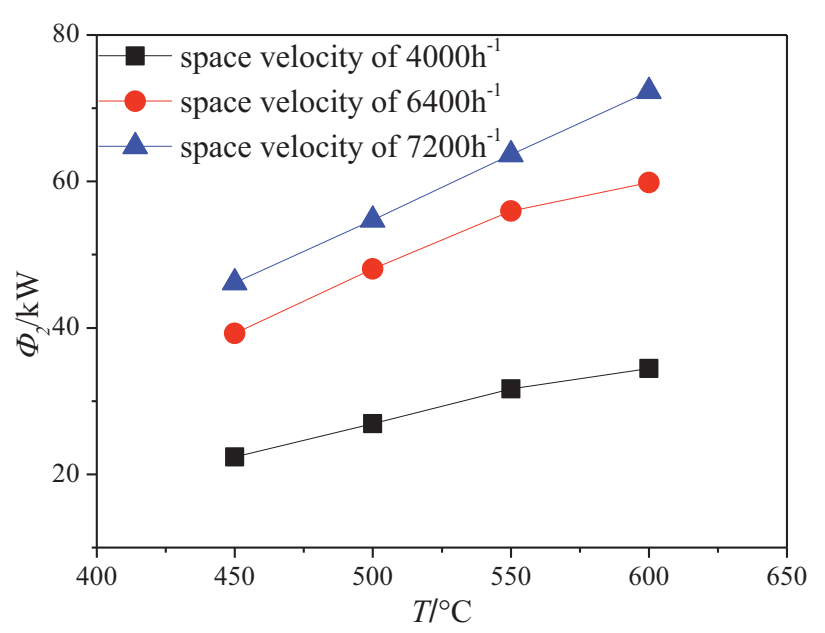

(b) Exhaust heat loss power

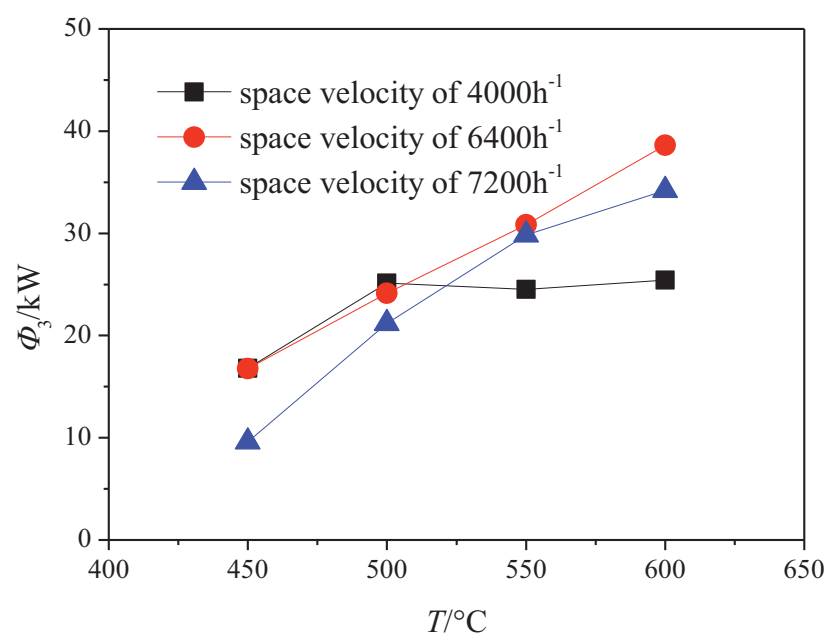

(c) Surface heat dissipation power

Fig. (8). Effects of oxidation bed inlet gas temperature on the energy balance terms under different space velocities.

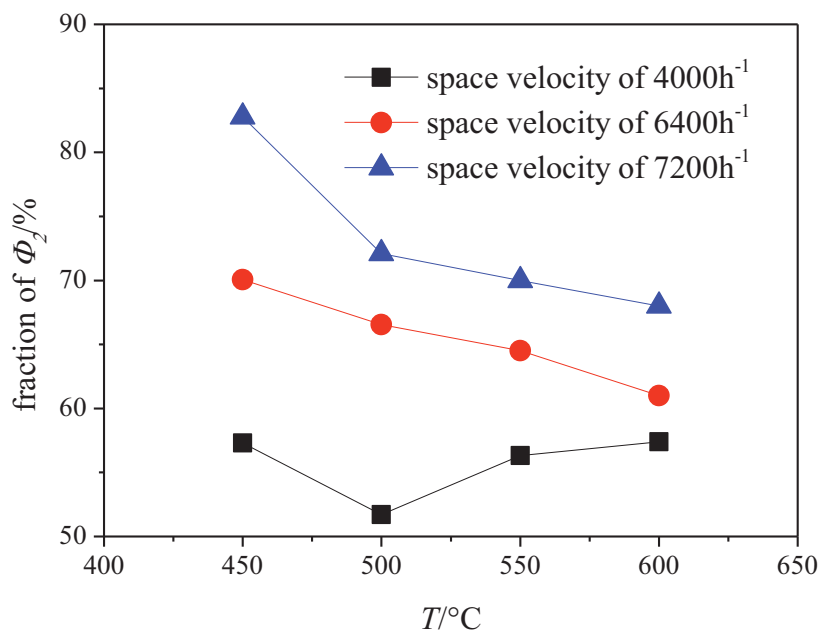

Fig. (9). Change of fraction of exhaust heat loss with oxidation bed inlet gas temperature under different space velocities. 


\section{CONCLUSION}

1) The exothermic oxidation power grows with the increase of the inlet methane volume concentration and the oxidation bed inlet temperature, yet decreases slightly when the space velocity increases to a certain value. This is because the increase of the inlet concentration and temperature improves the methane conversion rate, while the excessive space velocity reduces the methane conversion rate, so the overall methane oxidation heat is affected.

2) The inlet stream temperature and space velocity have obviously more influence on the exhaust heat loss power than the inlet stream methane volume concentration. This is due to that the methane volume concentration is in a very low operating range and has small effects on the methane conversion rate. While the rise of the inlet stream temperature improves the methane conversion rate evidently and the increase of the space velocity enhances the heat exchange of the gas and the oxidation bed, thus the exhaust takes more heat away.

3) The surface heat dissipation loss power increases significantly with the increase of the inlet stream concentration and temperature, especially at high space velocity, and with the increase of the space velocity firstly increases and then decreases. This is because with the increase of the inlet concentration and temperature the methane oxidation heat release grows and the heat exchange between the reaction chamber and the outside is enhanced. However, the methane conversion rate decreases when the space velocity increases to a certain value, then the oxidation heat release decreases and the heat exchange between the reaction chamber and the external reduces.

4) The fraction of the total heat loss accounted by the exhaust heat loss significantly reduces with the improvement of the inlet stream concentration and temperature, and yet obviously increases with the increase of the space velocity. In the whole operating parameter range of the preheating catalytic oxidation device, the heat recovery efficiency of the heat exchanger and the insulation layer performance should be optimized according to the exhaust heat loss and the surface heat dissipation loss under the high inlet concentration, temperature and space velocity condition, so as to reduce the overall heat loss and achieve the self-heating maintenance state.

\section{CONFLICT OF INTEREST}

The authors confirm that this article content has no conflict of interest.

\section{ACKNOWLEDGEMENTS}

The authors gratefully acknowledge the financial supports for this research from the National High Technology Research and Development Program ("863” Program) of China (Grant No. 2009AA063202), Shandong Province Natural Science Foundation Programs of China (Grant No. ZR2011EL017, No.ZR2013EEQ005and No.ZR2013EEQ008), Shandong Province Science and Technology Development Plan Project of China (Grant No. 2012GGX10417).

\section{REFERENCES}

[1] I. Karakurt, G. Aydin, and K. Aydiner, "Mine ventilation air methane as a sustainable energy source", Renew. Sustain. Energy Rev., vol. 15, no. 2, pp. 1042-1049, 2011.

[http://dx.doi.org/10.1016/j.rser.2010.11.030]

[2] F.Y. Sang, and G.Q. Zhao, "Comparison of vam utilization technology and equipments selection", Chin. Coalb. Meth, vol. 7, no. 2, pp. 44-46, 2010 .

[3] Z.L. Gao, Z.Q. Gao, Y.Q. Liu, and Q.Q. Su, "Actuality and development of harness and utilization of coalmine ven.tilation air methane", Energy Metall. Ind., vol. 29, no. 5, pp. 43-46, 2010.

[4] I. Karakurt, and G. Aydin, "Sources and mitigation of methane emissions by sectors: A critical review", Renew. Energy, vol. 39, no. 1, pp. 40-48, 2012.

[5] C.Ö. Karacan, F.A. Ruiz, M. Cotè, and S. Phipps, "Coal mine methane: A review of capture and utilization practices with benefits to mining safety and to greenhouse gas reduction", Int. J. Coal Geol., vol. 86, no. 2, pp. 121-156, 2011.

[http://dx.doi.org/10.1016/j.coal.2011.02.009]

[6] K. Warmuzinski, "Harnessing methane emissions from coal mining", Process Saf. Environ., vol. 86, no. 5, pp. 315-320, 2008. [http://dx.doi.org/10.1016/j.psep.2008.04.003]

[7] K. Gosiewski, and A. Pawlaczyk, "Catalytic or thermal reversed flow combustion of coal mine ventilation air methane: What is better choice and when?", Chem. Eng. J., vol. 238, no. 4, pp. 78-85, 2014.

[http://dx.doi.org/10.1016/j.cej.2013.07.039] 
[8] K. Gosiewski, A. Pawlaczyk, K. Warmuzinski, and M. Jaschik, "A study on thermal combustion of lean methane-air mixtures: Simplified reaction mechanism and kinetic equations", Chem. Eng. J., vol. 154, no. 1, pp. 9-16, 2009. [http://dx.doi.org/10.1016/j.cej.2009.03.045]

[9] K. Gosiewski, K. Warmuzinski, M. Jaschik, M. Tanczyk, and Y.S. Matros, "Homogeneous vs. catalytic combustion of lean methane-air mixtures in reverse-flow reactors", Chem. Eng. Sci., vol. 63, no. 20, pp. 5010-5019, 2008. [http://dx.doi.org/10.1016/j.ces.2007.09.013]

[10] K. Gosiewski, A. Pawlaczyk, and M. Jaschik, "Thermal combustion of lean methane-air mixtures: flow reversal research and demonstration reactor model and its validation", Chem. Eng. J., vol. 207-208, no. 5, pp. 76-84, 2012. [http://dx.doi.org/10.1016/j.cej.2012.07.044]

[11] Y.Q. Liu, R.X. Liu, and Y.X. Wang, "A Preheating Catalytic Oxidation Reactor for Coal Mine Ventilation Air Methane", China Patent CN202113840U, 2012.

[12] Y.Q. Liu, R.X. Liu, and Y.X. Wang, "A Preheating Catalytic Oxidation Reactor for Coal Mine Ventilation Air Methane with Multiple Reaction Chambers", China Patent CN102205207A, 2011.

[13] Y.Q. Liu, R.X. Liu, and Y.X. Wang, "A Preheating Catalytic Oxidation Reactor for Coal Mine Ventilation Air Methane with Burner Startup", China Patent CN102225321A, 2011.

[14] M.M. Mao, Y.Q. Liu, B. Zheng, R.X. Liu, and J. Meng, "Investigation of temperature distribution uniformity in a preheating catalytic oxidation bed", J. Chin. Coal Soc., vol. 40, no. 1, pp. 109-114, 2015.

[15] B. Zheng, Y.Q. Liu, R.X. Liu, S. Chen, M.M. Mao, and J. Meng, "Starting characteristics of ventilation air methane preheating catalytic oxidation reactor", J. Chin. Coal Soc., vol. 39, no. 6, pp. 1084-1088, 2014.

[16] B. Zheng, Y.Q. Liu, R.X. Liu, and J. Meng, "Catalytic oxidation of coal mine ventilation air methane in a preheat catalytic reaction", Int. J. Hydrogen Energy, vol. 40, no. 8, pp. 3381-3387, 2015. [http://dx.doi.org/10.1016/j.ijhydene.2015.01.020]

[17] B. Zheng, Y.Q. Liu, R.X. Liu, J. Meng, and M.M. Mao, "Experimental investigation of flow resistance in a coal mine ventilation air methane preheated catalytic oxidation reactor", J. Chem., vol. 2015, no. 11, 2015.

[18] M.M. Mao, Y.Q. Liu, R.X. Liu, B. Zheng, and J. Meng, "Experimental investigations of cold flow mass distribution and pressure drop characteristics in a structured honeycomb monolith bed", Open Mech. Eng. J., vol. 9, pp. 302-311, 2015.

[19] Z.L. Gao, Y.Q. Liu, and Z.Q. Gao, "Influence of packed honeycomb ceramic on heat extraction rate of packed bed embedded heat exchanger and heat transfer modes in heat transfer process", Int. Commun. Heat Mass., vol. 65, no. 9, pp. 76-81, 2015. [http://dx.doi.org/10.1016/j.icheatmasstransfer.2015.04.007]

[20] Z.L. Gao, Y.Q. Liu, and Z.Q. Gao, "Heat extraction characteristic of embedded heat exchanger in honeycomb ceramic packed bed", Int. Commun. Heat Mass., vol. 39, no. 10, pp. 1526-1534, 2012.

[http://dx.doi.org/10.1016/j.icheatmasstransfer.2012.09.010]

(C) Ming-Ming et al.; Licensee Bentham Open.

This is an open access article licensed under the terms of the Creative Commons Attribution-Non-Commercial 4.0 International Public License (CC BY-NC 4.0) (https://creativecommons.org/licenses/by-nc/4.0/legalcode), which permits unrestricted, non-commercial use, distribution and reproduction in any medium, provided the work is properly cited. 